\title{
Does the diagnosis influence the outcome in a multimodal outpatient pain management program for low back pain and sciatica? A comparative study
}

This article was published in the following Dove Press journal:

Journal of Multidisciplinary Healthcare

12 July 2012

Number of times this article has been viewed

\author{
Juraj Artner \\ Stephan Kurz \\ Balkan Cakir \\ Heiko Reichel \\ Friederike Lattig \\ Department of Orthopaedics, \\ University of Ulm, Germany
}

Correspondence: Juraj Artner Department of Orthopaedics, University of Ulm, RKU, Oberer Eselsberg 45, 8908I Ulm, Germany Tel+49 73I I77 5III

Email j.artner@gmail.com

\begin{abstract}
The literature describes multimodal pain-management programs as successful therapy options in the conservative treatment of chronic low back pain. Yet, the intensity and inclusion criteria of such programs remain debatable. In many studies, the pain originating from spinal structures is described as nonspecific low back pain - a diffuse diagnosis without serious implications. The purpose of this study is to compare the short-term outcomes between patients suffering from sciatica due to a discus intervertebralis herniation and those suffering from low back pain caused by facet joint disease after 3 weeks of treatment in an intense multimodal outpatient program in the Department of Orthopaedic Surgery at the university hospital.

Keywords: chronic low back pain, sciatica, interdisciplinary management, discus herniation, spondylarthritis
\end{abstract}

\section{Introduction}

The need for conservative spinal interventions is increasing, corresponding to the increasing number of spinal disorders. The literature describes multimodal therapy programs as successful therapy options in the treatment of acute and chronic low back pain (LBP). ${ }^{1-3}$ The multimodal outpatient program at the University of Ulm Department of Orthopaedics has provided an intense multimodal treatment on an outpatient basis for several years. It combines group therapy with individual approaches, pain management, medication, spinal injection procedures, physiotherapy, medical training therapy, spa, massage, transcutaneous electrical nerve stimulation (TENS), ergotherapy, traction, and back school. The therapy team consists of a physician and 5-7 physiotherapists with optional psychosomatic treatment. Such a constellation of experts provides an intense level of therapy for the patient. Despite many reports in the literature, this study does not use the term "nonspecific" low back pain, but, rather, aims to determine a specific diagnosis based on clinical examination, radiography, and magnetic resonance tomography (MRT). The purpose of this study is to compare the short-term outcomes between patients suffering from sciatica due to a discus intervertebralis herniation and those suffering from low back pain caused by facet joint disease after 3 weeks of intense multimodal outpatient pain management program.

\section{Treatment regime specifications}

The intense interdisciplinary program is performed on an outpatient basis. The duration of the program is 3 weeks, occurring daily between 8 am and $5 \mathrm{pm}$. It combines a broad spectrum of active and passive therapy elements, performed in groups as well as on an individual basis. The mean goals of the program are pain reduction and functional restoration. 
The group size is limited to 12 patients to allow for adequate individual attention. The core elements of the therapy regime are medical, physiotherapy, and psychological, using a collaborative, interdisciplinary, and nonhierarchical team approach. An experienced orthopedic surgeon and an anesthesiologist are responsible for the medical treatment, indication, modification in medication or treatment regime, further diagnosis, and interventional pain management. The orthopedic surgeon supervises each patient's progress two times per day. Between five and seven experienced physical therapists provide group and individual exercise, back school, manipulation, massage, spa therapy, TENS, superficial heat application, traction, ultrasonography, and physical relaxation techniques. A separate ergotherapy group is included in the treatment regime to improve patients' occupational and private functionality. An experienced psychologist is responsible for psychological therapy (psychosomatic treatment and psychotherapy) in a group setting. Individual psychological therapy is optional, but is utilized by an increasing number of patients. The team discusses each patient's history, therapy approach, and progress in 2-3 meetings per week. Table 1 describes the separate components of the treatment regime and the frequency of each component's application.

\section{Materials and methods}

One hundred fifty-six (out of 261) patients who underwent the intense interdisciplinary treatment between 2009 and 2011 were included in this retrospective study. The inclusion criteria were as follows: a definitive diagnosis of lumbar disc

Table I Treatment regime (frequency of modalities in hours per week)

\begin{tabular}{ll}
\hline Type of therapy & Frequency \\
\hline Medical control & $2 \times$ daily \\
Exercise therapy & $4 \times$ weekly \\
Spinal injections & $2-8$ injections \\
Back school & $4 \times$ weekly \\
Medical training therapy & $4 \times$ weekly \\
Sport therapy & $4 \times$ weekly \\
Spa therapy & $4 \times$ weekly \\
Massage & $4-5 \times$ weekly \\
Electrotherapy & $4-5 \times$ weekly \\
Fango & $4-5 \times$ weekly \\
Behavioral (relaxation) therapy & $2 \times$ weekly \\
Feldenkrais & $2 \times$ weekly \\
Traction therapy & $1-5 \times$ weekly \\
Walking & $1 \times$ weekly \\
Ergotherapy & $1 \times$ weekly \\
Psychosomatic therapy & $1-2 \times$ weekly* \\
\hline Note: *Group therapy (variable individual sessions I-2 $\times$ weekly).
\end{tabular}

herniation with sciatica $(n=107)$ or facet joint arthritis with low back pain $(n=49)$, based on clinical and radiographic (plain radiograms and MRT) examination. The radiographic criteria proposed by Lane et $\mathrm{al}^{4}$ were used to analyze the plain radiographs. The criteria outlined by Pfirrmann et $\mathrm{al}^{5}$ were used to analyze the T2-weighted sagittal magnetic resonance imaging (MRI) scans for lumbar disc degeneration, in combination with disc extrusion in the MRI and clinical findings of persistent or intermittent nerve root entrapment. Finally, the criteria proposed by Weishaupt et al were used to analyze the MRI imaging for lumbar facet joint degeneration in combination with changes in plain radiographs (sclerosis, hypertrophy) and clinical findings of local or pseudoradicular lumbar pain. ${ }^{6}$ No other spinal diseases or systemic disorders contributed to the symptoms. Patients with overlapping symptoms and multilocular pathology (spondylarthritis and discus hernia) who could not be characterized precisely after spinal injections into one of the two subgroups were excluded from the retrospective analysis. The duration of symptoms was at least 12 weeks and every patient received standard therapy before entering the program. Every patient enrolled in the study was treated for 3 weeks in the program and signed an informed consent about the use of the datasets (history, numerical rating scale [NRS], and Oswestry Disability Questionnaire [ODQ]) acquired at the baseline and at the end of the therapy regime.

The exclusion criteria were infection, severe instability, pregnancy, age under 18 years, fracture, anticoagulation, myelopathy, somatoform disease, substance abuse, severe cardiopulmonary alteration, weak overall fitness, paresis, and incompliance. The mean pain intensities of sciatica and LBP (low back pain) were documented using the 10-point NRS. In cases of coexistence of LBP and sciatica, the more intense pain component was documented. Functional impairment was assessed using the ODQ. Both tools are validated and frequently used to assess the outcome of surgical and nonsurgical treatments for low back pain. ${ }^{7}$ The mean NRS reduction and ODI (Oswestry Disability Index) improvement were analyzed with statistical software (SPSS Statistics 17.0; IBM Corporation, Armonk, NY). First, the normal (Gaussian) distribution of variables was excluded using a histogram, the Kolmogorov-Smirnov test with a Lilliefors significance correction, and the Shapiro-Wilk test. Next, the outcomes were analyzed using the Mann-Whitney test (U-test) and the Kolmogorov-Smirnov test (Z-test) to identify unpaired variables and a significant difference between the discus hernia cohort and the facet joint disease group. ${ }^{8,9}$ The sample power size was calculated with a $t$-test analysis (post hoc one-tailed analysis 
for means). The results of the Z-test were reproduced with Minitab 16 (Minitab Inc, State College, PA).

\section{Results}

One hundred fifty-six (out of 261) NRS and ODQ outcomes were analyzed (sciatica in lumbar discus hernia group, $\mathrm{n}=107$; low back pain in spondylarthrosis, $\mathrm{n}=49$ ). A sample size power of 0.9985 was calculated using a $t$-test analysis (post hoc one-tailed analysis for means, effect size $d=0.8, \alpha=0.05$, critical $t<154>=1.6548$, delta $=4.6379)$.

The mean reduction of NRS was calculated to be -4.31 points in the discus hernia group (mean $=-4.31,95 \%$ CI: -4.66 to $-3.96, \mathrm{SD}=1.82)$ and -4.43 in the facet joint disease group $($ mean $=-4.43,95 \%$ CI: -5.00 to -3.85 , $\mathrm{SD}=2.00)$ (see Figure 1A). The mean disability reduction (measured by ODI) was calculated to be $-10.47 \%$ in the discus hernia group $($ mean $=-10.47 \%, 95 \%$ CI: $-12.58 \%$
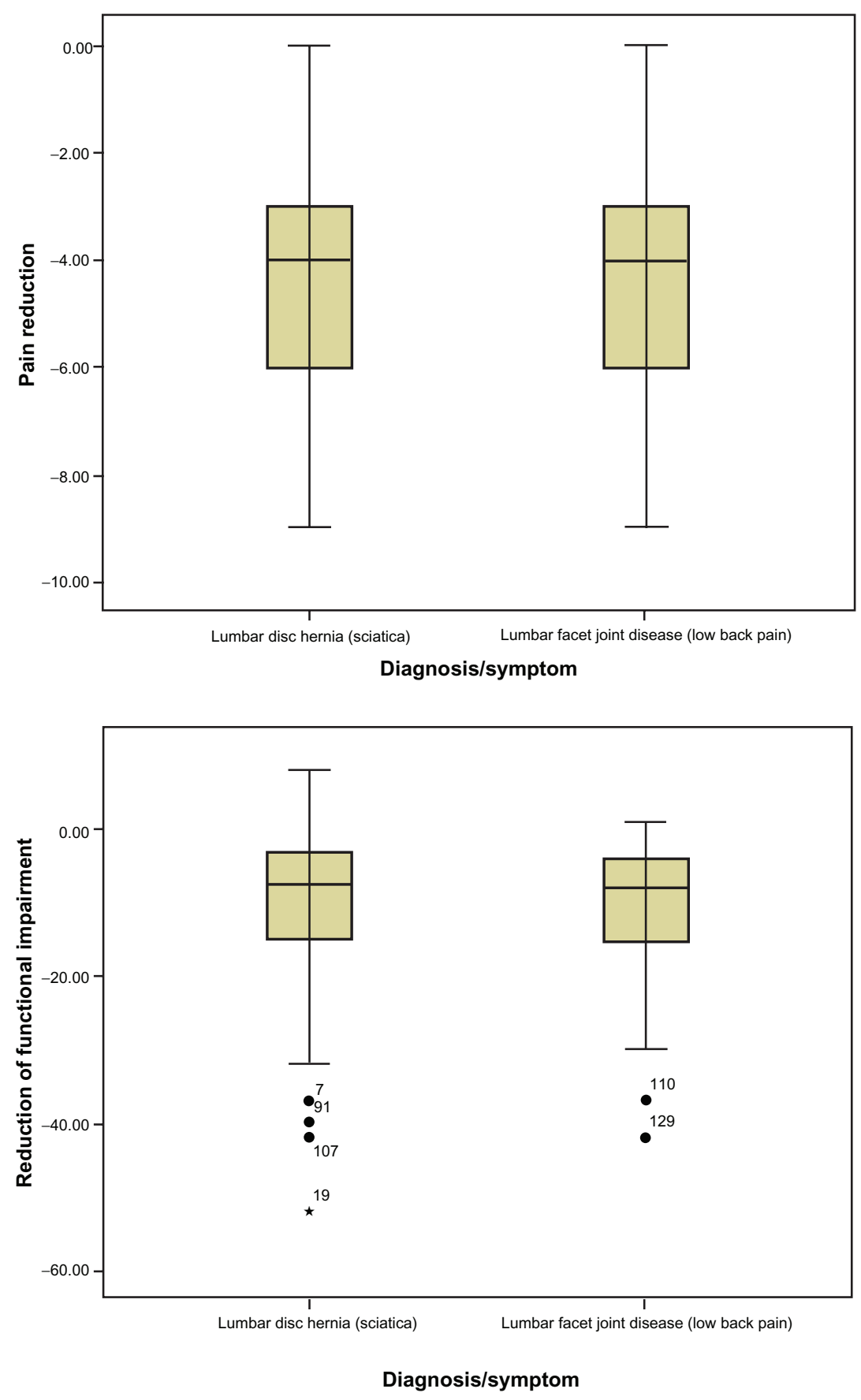

Figure I Boxplots comparing the reduction of pain $(\mathbf{A})$ and functional disability (B). 
Table 2 Subgroup characteristics and outcomes

\begin{tabular}{lll}
\hline & $\begin{array}{l}\text { Sciatica } \\
\text { group }\end{array}$ & $\begin{array}{l}\text { Low back } \\
\text { pain group }\end{array}$ \\
\hline $\begin{array}{l}\text { Total }(\mathrm{n}) \\
\text { Sex }\end{array}$ & 107 & 49 \\
$\quad$ Male & 46 & 16 \\
$\quad$ Female & $6 \mathrm{I}$ & 33 \\
Age (years) & & \\
$\quad$ Mean & 57 & $6 \mathrm{I}$ \\
$\quad$ Range & $22-79$ & $28-78$ \\
$\begin{array}{l}\text { Baseline pain intensity } \\
\text { (NRS I0-point scale) }\end{array}$ & 6 & 6 \\
$\begin{array}{l}\text { Baseline functional } \\
\text { impairment (ODI\%) }\end{array}$ & 34 & 35 \\
Pain intensity after 3 weeks (NRS) & 2 & 2 \\
Functional impairment after & 23 & 24 \\
3 weeks (ODI\%) & & \\
Pain reduction $(\Delta$ NRS/\%) & $4 / 66 \%$ & $4 / 66 \%$ \\
Functional improvement $(\Delta$ ODI/\%) & $1 \mathrm{I} / 32.35 \%$ & $1 \mathrm{I} / 3 \mathrm{I} .43 \%$ \\
\hline
\end{tabular}

Abbreviations: $n$, number; NRS, numerical rating scale; ODI, Oswestry Disability Index.

to $-8.36 \%$, SD $=10.94)$, and $-10.88 \%$ for the facet joint disease group $($ mean $=-10.88 \%, 95 \% \mathrm{CI}:=-13.84 \%$ to $-7.92 \%, \mathrm{SD}=10.31$ ) (see Figure $1 \mathrm{~B}$ ). Neither of the groups presented a Gaussian distribution of variables in their outcomes (graphical analysis histogram, Kolmogorov-Smirnov test with a Lilliefors significance correction $=0.000,0.004$; Shapiro-Wilk test $=0.002,0.126$ ). The Mann-Whitney U-test and the Z-test were used to calculate the significance of the difference between the results in both groups (H0-hypothesis: the results in the improvement of pain self-assessment and functionality in both groups were equal). The hypothesis of equality (H0) was accepted after calculating a two-tailed significance of 0.757 for pain reduction, 0.702 for ODI reduction using the Mann-Whitney U-test, a two-tailed significance of 1.000 for pain reduction, and 0.997 for ODI reduction using the Kolmogorov-Smirnov Z-test. The U-test was also controlled and reproduced using Minitab 16. Table 2 presents the characteristics of the subgroup.

There were no complications or dropouts during the therapy regime in either of the groups.

\section{Discussion}

Therapy for chronic LBP and sciatica is complicated. Most unimodal treatments fail to restore functionality and adequately reduce pain. ${ }^{10}$ One reason for this failure is the biopsychosocial aspect of chronic pain, which is not addressed in unimodal therapy. With its focus on functional restoration, multimodal treatment is a promising option for patients with chronic LBP. ${ }^{11}$
The results of this comparative study demonstrate equal short-term results in the intense interdisciplinary treatment of patients with lumbar discus herniation with sciatica and patients with LBP due to facet joint disease.

Despite the efficacy of intense interdisciplinary treatment regimes, there is a lack of research on how this method affects specific spinal disorders. According to the results of this study, we conclude that patients suffering from sciatica due to intervertebral disc herniation and patients with chronic back pain due to facet joint disease have similar short-term results in response to intense interdisciplinary treatment. Compared to the results for chronic LBP treatment regimes presented in the literature, both groups presented good clinical outcomes. ${ }^{11}$

Despite many misleading reports in the literature, this study does not use the term "nonspecific" LBP, but, rather, aims to determine a specific diagnosis based on clinical examination, radiography, and MRT. ${ }^{12-14}$ Although there was no significant difference in the outcomes from both groups, the results do not justify the use of nonspecific diagnoses.

The results of this study must be interpreted carefully, because imaging and examination findings do not always correlate with symptoms in spinal disorders, nor do they correspond to subjective pain intensity. ${ }^{15,16}$ Therefore, forcing a specific spinal-disorder diagnosis is problematic. Wrong diagnoses may lead to overdiagnosis, labeling effects experienced by the patient, and, ultimately, further chronification of pain. ${ }^{17}$ On the other hand, specific anatomical diagnoses have direct therapeutic implications in orthopedics, especially for the use of spinal injection procedures (epidural, periradicular or facet joint injections). ${ }^{18}$ In addition to the therapeutic benefit of symptom control, image-guided injections also contribute to higher diagnostic accuracy (eg, verification of facetogenic versus radicular pain). ${ }^{19,20}$ Reports in the literature conclude that $67 \%-75 \%$ of LBP cases can be accurately diagnosed as discogenic, facetogenic, or sacroiliac pain using imageguided injections. ${ }^{21-23}$

\section{Disclosure}

The authors report no conflicts of interest in this work.

\section{References}

1. van Tulder MW, Koes BW, Bouter LM. Conservative treatment of acute and chronic nonspecific low back pain. A systematic review of randomized controlled trials of the most common interventions. Spine (Phila Pa 1976). 1997;22(18):2128-2156. 
2. Rainville J, Jouve CA, Hartigan C, Martinez E, Hipona M. Comparison of short- and long-term outcomes for aggressive spine rehabilitation delivered two versus three times per week. Spine J. 2002;2: 402-407.

3. Hayden JA, van Tulder MW, Malmivaara AV, Koes BW. Meta-analysis: exercise therapy for nonspecific low back pain. Ann Intern Med. 2005; 142(9):765-775.

4. Lane NE, Nevitt MC, Genant HK, Hochberg MC. Reliability of new indices of radiographic osteoarthritis of the hand and hip and lumbar disc degeneration. J Rheumatol. 1993;20(11):1911-1918.

5. Pfirrmann CW, Metzdorf A, Zanetti M, Hodler J, Boos N. Magnetic resonance classification of lumbar intervertebral disc degeneration. Spine (Phila Pa 1976). 2001;26(17):1873-1878.

6. Weishaupt D, Zanetti M, Boos N, Hodler J. MR imaging and CT in osteoarthritis of the lumbar facet joints. Skeletal Radiol. 1999;28(4): 215-219.

7. Mannion A, Elfering A, Staerkle R, et al. Outcome assessment in low back pain: how low can you go? Eur Spine J. 2005;14(10):1014-1026.

8. Mann HB, Whitney DR. On a test of whether one of two random variables is stochastically larger than the other. Annals of Mathematical Statistics. 1947;18:50-60.

9. Kasuya E. Mann-Whitney U test when variances are unequal. Animal Behavior. 2001;61:1247-1249.

10. Turk DC. Clinical effectiveness and cost-effectiveness of treatments for patients with chronic pain. Clin J Pain. 2002;18(6):355-365.

11. Luk KDK, Wan TWM, Wong YW, et al. A multidisciplinary rehabilitation programme for patients with chronic low back pain: a prospective study. J Orthop Surg (Hong Kong). 2010;18(2):131-138.

12. Rodriguez-Blanco T, Fernández-San-Martin I, Balagué-Corbella M, Berenguera A, et al. Study protocol of effectiveness of a biopsychosocial multidisciplinary intervention in the evolution of non-speficic sub-acute low back pain in the working population: cluster randomised trial. $B M C$ Health Serv Res. 2010;10:12.

13. Kuijpers T, van Middelkoop M, Rubinstein SM, et al. A systematic review on the effectiveness of pharmacological interventions for chronic non-specific low-back pain. Eur Spine J. 2011;20(1):40-50.
14. Koes BW, van Tulder M, Lin CWC, Macedo LG, McAuley J, Maher C. An updated overview of clinical guidelines for the management of non-specific low back pain in primary care. Eur Spine J. 2010;19(12):2075-2094.

15. Manchikanti L, Pampati VS, Fellows B, Baha A. The inability of the clinical picture to characterize pain from facet joints. Pain Physician. 2000;3(2):158-166.

16. Schwarzer AC, Aprill CN, Derby R, Fortin J, Kine G, Bogduk N. Clinical features of patients with pain stemming from the lumbar zygapophysial joints. Is the lumbar facet syndrome a clinical entity? Spine (Phila Pa 1976). 1994;19(10):1132-1137.

17. Abenhaim L, Rossignol M, Gobeille D, Bonvalot Y, Fines P, Scott S The prognostic consequences in the making of the initial medical diagnosis of work-related back injuries. Spine (Phila Pa 1976). 1995;20(7) 791-795.

18. Bogduk N, McGuirk B. An algorithm for precision diagnosis. In: Bogduk N, McGuirk B, editors. Medical Management of Acute and Chronic Low Back Pain. An Evidence-Based Approach: Pain Research and Clinical Management. Amsterdam: Elsevier Science; 2002:177-186.

19. Seghal N, Shah RV, McKenzie-Brown AM, Everett CR. Diagnostic utility of facet (zygapophysial) joint injections in chronic spinal pain: A systematic review of evidence. Pain Physician. 2005;8(2):211-224.

20. van Akkerveeken PF. The diagnostic value of nerve root sheath infiltration. Acta Orthop Scand Suppl. 1993;251:61-63.

21. Maigne JY, Aivaliklis A, Pfefer F. Results of sacroiliac joint double block and value of sacroiliac pain provocation tests in 54 patients with low back pain. Spine (Phila Pa 1976). 1996;21(16):1889-1892.

22. Schwarzer AC, Aprill CN, Derby R, Fortin J, Kine G, Bogduk N. The prevalence and clinical features of internal disc disruption in patients with chronic low back pain. Spine (Phila Pa 1976). 1995;20(17): 1878-1883.

23. Schwarzer AC, Aprill CN, Derby R, Fortin J, Kine G, Bogduk N. The false-positive rate of uncontrolled diagnostic blocks of the lumbar zygapophysial joints. Pain. 1994;58(2):195-200.
Journal of Multidisciplinary Healthcare

\section{Publish your work in this journal}

The Journal of Multidisciplinary Healthcare is an international, peerreviewed open-access journal that aims to represent and publish research in healthcare areas delivered by practitioners of different disciplines. This includes studies and reviews conducted by multidisciplinary teams as well as research which evaluates the results or conduct of such teams or

\section{Dovepress}

healthcare processes in general. The journal covers a wide range of areas and welcomes submission from practitioners at all levels, from all over the world. The manuscript management system is completely online and includes a very quick and fair peer-review system. Visit http://www.dovepress.com/testimonials.php to read real quotes from published authors. 